Original Research Article

\title{
A randomized controlled study on expectant management of incomplete abortions caused by self medication
}

\author{
Beenu Kushwah ${ }^{1}$, Devendra Singh Kushwah ${ }^{2 *}$
}

${ }^{1}$ Department of Gynecology, S.S. Medical College Rewa, Madhya Pradesh, India ${ }^{2}$ Department of Pharmacology, Gajra Raja Medical College, Gwalior, Madhya Pradesh, India

Received: 15 April 2019 Accepted: 13 May 2019

\section{*Correspondence to:}

Dr. Devendra Singh Kushwah, Email: dev_singh433@

yahoo.com

Copyright: (C) the author(s), publisher and licensee Medip Academy. This is an openaccess article distributed under the terms of the Creative Commons Attribution NonCommercial License, which permits unrestricted noncommercial use, distribution, and reproduction in any medium, provided the original work is properly cited.

\begin{abstract}
Background: Medical method of termination of pregnancy is a very effective method when used as per recommended regimen and under proper supervision. Self-administration of these drugs has become a very common practice these days, resulting in incomplete abortion because of improper use. Traditionally surgical curettage has been the preferred mode of treatment for these cases but is associated with very high complication rates. Expectant management of incomplete abortion has been recently adopted as a better method of management of incomplete abortions worldwide. Present study compares expectant management with surgical curettage in cases of incomplete abortions caused by self medication.
\end{abstract}

Methods: It was one-year prospective randomized controlled study. Total of 220 patients were recruited for the study out of which 103 were randomized to undergo expectant management while 117 to undergo surgical curettage. Results were compared using chi square test..

Results: Success rate of expectant and surgical management was found to be $82 \%$ and $95 \%$ respectively. Complication rate was found to be comparable in both the group while acceptability of expectant management was found to be much higher in expectant group. However, significantly more unplanned admissions and unplanned surgical curettage occurred after expectant management than surgical management.

Conclusions: Expectant management is a safe and efficacious option in carefully selected cases. If used properly it can avoid complications associated with surgical management and therefore should be utilized whenever suitable.

Keywords: Expectant management, Self medication, Surgical curettage

\section{INTRODUCTION}

Medical method of pregnancy termination has been legalized in India since 2003. ${ }^{1}$ It is a very safe and effective option if used as per WHO guidelines and under proper medical super vision, with a success rate of almost 92$97 \% .^{2,3}$ As per medical termination of pregnancy (MTP) act of India, these pills can be prescribed only by a registered medical practitioner after fulfilling certain conditions. $^{1}$ In spite of clear guidelines and recommendations available, self administration of abortion pills at home has become rampant, most possibly due to ignorance $\&$ huge shortage of doctors in peripheral areas. While practicing self administration of abortion pills, proper drug regimen is not followed, chances of incomplete abortions are high. According to our hospital's last 3 years statistics two third of total incomplete abortion cases that come to the hospital, are caused by intake of abortifacient drugs at home which for obvious reasons puts a high burden on our department in terms of surgical curettage to be performed on daily basis. In past many studies have observed that after medical abortions there is are very high chances of prolonged bleeding per vaginum. $^{4,5}$ which mostly resolves by $3-4$ weeks time, therefore expectant management may help in majority of cases. ${ }^{6}$ Also, it is a known fact that surgical curettage apart from putting burden on health care facilities, bears risk of 
complications like; cervical tears, uterine perforation, infection and post abortal adhesions etc. ${ }^{7}$ During last two decades many studies have compared expectant management of incomplete abortions with surgical curettage, caused by medical method and observed that expectant management has a very good efficacy rate with lesser complication rate. ${ }^{8-10}$ Recent NICE guideline number 154 and Cochrane review also recommend use of expectant management in case of uncomplicated medical abortions. ${ }^{11-13}$ Although expectant management have been proved an efficacious method over surgical curettage for incomplete abortions caused by supervised medical abortions, present study is of first kind that compares expectant management with surgical curettage for incomplete abortions caused by unsupervised self medication.

\section{METHODS}

It was a prospective Randomized controlled study done over a period of one year from April 2018 to March 2019 at Shyam Shah Medical College and associated hospitals, Rewa, India. Ethical approval was obtained by Institutional Ethical Committee (Human studies), Shyam Shah Medical College, Rewa. Women in early pregnancy who fulfilled the inclusion criteria and gave consents to be a part of study were randomly categorized in two groups by the use of random number computer tables. Group 1 was allocated expectant management and group 2 was allocated surgical management in the form of curettage. All women were explained about the warning signs and were followed up after 15 days and at 1 and 2 months after first visit. Results were entered in a present format and were analyzed subsequently.

\section{Inclusion criteria}

- Incomplete abortion caused by self medication at home for $\leq 15$ days from the day of allocation, pregnancy of less than 13 weeks gestation,

- Fetus already expelled and presence of retained products of conception or endometrial thickness of more than $10 \mathrm{~mm}$ on USG,

- Hemodynamically stable,

- No signs of local or systemic infections.

- $\quad$ No major medical or surgical sickness.

\section{Statistical analysis}

Appropriate statistical tests were applied as per the need. We tested differences for statistical significance using chi square test and data were analyzed using the Statistical Package of the Social Sciences (SPSS, version 21.0).

\section{Outcomes}

A successful outcome was defined as Endometrial thickness of $<10 \mathrm{~mm}$ at 1 month follow up. Secondary outcomes were associated complications like need for emergency evacuation due to heavy bleeding per vaginum, persistent bleeding per vaginum at 1 month follow up, any sign symptom of infection and curettage related complications like cervical tear and perforation.

\section{RESULTS}

During this period a total of 434 women qualified for the study out of which 311 finally consented to be a part of allocated group and were randomized in group 1 and group 2. Group 1 consisted of 156 women while group 2 consisted of 155 women. Out of 156 women in Group 1, 39 lost to follow up and this number was 52 in group 2 out of total 155. Therefore, for data analysis 103 women in group 1 and 117 women in group 2 were finally available. Baseline characteristics of both the groups were comparable (Table 1).

Table 1: Baseline characteristics of study population.

\begin{tabular}{|lll|}
\hline Baseline characteristic & $\begin{array}{l}\text { Group-1 } \\
\text { (expectant) } \\
\text { N= 103 }\end{array}$ & $\begin{array}{l}\text { Group-2 } \\
\text { (surgical) } \\
\text { N=117 }\end{array}$ \\
\hline Age in years, mean (SD) & $28.4(6.2)$ & $29.1(7)$ \\
\hline Nulliparous, N (\%) & $32(31)$ & $47(40)$ \\
\hline Multiparous, N (\%) & $71(69)$ & $70(60)$ \\
\hline $\begin{array}{l}\text { Gestational age in } \\
\text { weeks, mean (SD) }\end{array}$ & $9.2(2.2)$ & $10(1.8)$ \\
\hline $\begin{array}{l}\text { Previous history of } \\
\text { medical abortion, N (\%) }\end{array}$ & $47(46)$ & $59(50)$ \\
\hline
\end{tabular}

In expectant group 19 women underwent surgical curettage within 1 month of allocation, out of which 7 were performed on emergency basis while 12 because of persistent vaginal bleeding. In surgical group 6 women underwent repeat curettage due to persistent vaginal bleeding, out of which one was done on emergency basis. In present study, expectant management had a success rate of $82 \%$ while surgical management had a success rate of $95 \%$.

In expectant group, 7 women had complication in the form of heavy bleeding requiring emergency evacuation out of which 5 women required blood transfusion as well, 6 women developed pelvic inflammatory disease out of which 4 women had undergone surgical evacuation for persistent bleeding.

In surgical curettage group, 29 women developed some kind of complications, out of these 16 women developed pelvic inflammatory disease on follow up, one woman had to undergo repeat emergency evacuation, 2 women had cervical tears, 3 women had uterine perforation and 9 women developed Asherman syndrome on follow up visit in the form of amenorrhea/ oligomenorrhea.

Total 21 women in expectant group and 63 women in curettage group required additional analgesia. 71 women in group 1 and 41 women in group 2 found their method of treatment acceptable and were willing to recommend it to 
others, thereby found expectant method more convenient than surgical method (Table 2).

Table 2: Clinical outcomes of study population.

\begin{tabular}{|lll|}
\hline Outcome & $\begin{array}{l}\text { Group 1 } \\
(\mathbf{N}=103)\end{array}$ & $\begin{array}{l}\text { Group 2 } \\
(\mathbf{N}=117)\end{array}$ \\
\hline Success rate, N (\%) & $84(82 \%)$ & $111(95 \%)$ \\
\hline Complication rate, N (\%) & $13(13 \%)$ & $29(25 \%)$ \\
\hline Emergency evacuation & $7(7 \%)$ & $1(.8 \%)$ \\
\hline Blood transfusion & $5(5 \%)$ & 0 \\
\hline $\begin{array}{l}\text { Pelvic inflammatory } \\
\text { disease }\end{array}$ & $6(6 \%)$ & $16(14 \%)$ \\
\hline Cervical tear & 0 & $2(2 \%)$ \\
\hline Uterine perforation & 0 & $3(3 \%)$ \\
\hline Asherman syndrome & 0 & $9(8 \%)$ \\
\hline $\begin{array}{l}\text { Requirement for } \\
\text { additional analgesia }\end{array}$ & $21(20 \%)$ & $63(54 \%)$ \\
\hline Acceptability & $71(69 \%)$ & $41(35 \%)$ \\
\hline
\end{tabular}

\section{DISCUSSION}

Traditionally surgical curettage has remained a standard method of treatment after incomplete abortion which has been caused by medical method of termination of pregnancy. But it is associated with many immediate and long term complications. During last decade many researchers have observed that expectant management has a comparable success rate and is associated with much lesser complication rate. In present study success rate of expectant management and surgical management was found to be $82 \%$ and $95 \%$ respectively, which is comparable to other studies done by various researchers over the time..$^{9,14,15}$

Infection rate was found to be higher in surgical group which is comparable with other studies. ${ }^{14,16}$ The rate of emergency evacuation was found to be much higher in expectant group (7\%) than surgical group $(0.8 \%)$ which is in accordance with previous studies. ${ }^{17,18}$ Rate of procedure related complication was nil in expectant group while it was in the range of $2-3 \%$ in surgical group in the form of cervical tear and uterine perforation. Need for additional analgesia was found to be very high in surgical group for obvious reasons. Acceptability of the allocated method was found to be significantly higher in expectant group than surgical group, most common reason being less pain and apprehension of undergoing a surgical intervention.

\section{CONCLUSION}

Expectant management of incomplete abortion caused by abortifacient drugs is an acceptable method and has good success rate, therefore should be utilized in carefully selected cases. As surgical management is associated with many side effects, a proper counseling should be offered regarding option of expectant management to all women selecting surgical curettage.
Funding: No funding sources

Conflict of interest: None declared

Ethical approval: The study was approved by the Institutional Ethics Committee

\section{REFERENCES}

1. Government of India. The medical termination of pregnancy rules (amendment). 2003. Ministry of Health and Family Welfare. Department of Family Welfare: Notification, New Delhi, the 13th June 2003. Available at: http://mohfw.nic.in.

2. World Health Organization. Safe abortion: technical and policy guidelines for health systems (online). 2012;1-7. Available at: www.apps.who.int/iris/bitstream/10665/709141/9789 241548434 eng.pdf.

3. Ankum WM. Management of first trimester miscarriage. Br J Hosp Med. 2008;69:380-3.

4. Creinin MD, Harwood B, Guido RS, Fox MC, Zhang J. Endometrial thickness after misoprostol use for early pregnancy failure. Int $\mathbf{J}$ Gynaecol Obstet 2004;86:22-6.

5. Davis AR, Hendlish SK, Westhoff C, Frederick MM, Zhang J, Gilles JM, Barnhart K, Creinin MD. Bleeding patterns after misoprostol vs surgical treatment of early pregnancy failure: results from a randomized trial. Am J Obstet Gynecol. 2007;196:31.e31-7.

6. Debby A, Golan A, Sadan O, Rotmensch S, Malinger G. Sonographic characteristics of the uterine cavity following first-trimester uterine evacuation. Ultrasound Obstet Gynecol. 2008;31:555-9.

7. Hooker AB, Lemmers M, Thurkow AL, Heymans MW, Opmeer BC, Brölmann HA, et al. Systematic review and meta-analysis of intrauterine adhesions after miscarriage: prevalence, risk factors and longterm reproductive outcome. Hum Reprod Update. 2013;20(2):262-78.

8. Kong GW, Lok IH, Yiu AK, Hui AS, Lai BP, Chung TK. Clinical and psychological impact after surgical, medical or expectant management of first-trimester miscarriage-a randomised controlled trial. Aust N Z J Obstet Gynaecol. 2013;53:170-7.

9. Trinder J, Brocklehurst P, Porter R, Read M, Vyas S, Smith L. Management of miscarriage: expectant, medical, or surgical? Results of randomised controlled trial (miscarriage treatment (MIST) trial). Br Med J. 2006;332:1235-40.

10. You JH, Chung TK. Expectant, medical or surgical treatment for spontaneous abortion in first trimester of pregnancy: a cost analysis. Hum Rep. 2005;20:28738.

11. Nanda K, Peloggia A, Grimes D, Lopez L, Nanda G. Expectant care versus [4] surgical treatment for miscarriage. Coch Database Sys Rev. 2006;(2):CD003518.

12. Casikar I, Bignardi T, Riemke J, Alhamdan D, Condous G. Expectant management of spontaneous first-trimester miscarriage: prospective validation of 
the '2-week rule'. Ultrasound Obstetr Gynecol. 2010;35(2):223-7.

13. Jurkovic D, Overton C, Bender-Atik R. Diagnosis and management of first trimester miscarriage. BMJ. 2013;346:f3676.

14. Wieringa-de Waard M, Hartman EE, Ankum WM, Reitsma JB, Bindels PJE, Bonsel GJ. Expectant management versus surgical evacuation in first trimester miscarriage: health-related quality of life in randomized and non-randomized patients. Hum Reprod. 2002;17:1638-42.

15. Lemmers M, Verschoor MA, Oude Rengerink K, Naaktgeboren C, Opmeer BC, Bossuyt PM, et al.MisoREST: surgical versus expectant management in women with an incomplete evacuation of the uterus after misoprostol treatment for miscarriage: a randomized controlled trial. Hum Reprod. 2016;31(11):2421-7.

16. Bagratee JS, Khullar V, Regan L, Moodley J, Kagoro H. A randomized controlled trial comparing medical and expectant management of first trimester miscarriage. Hum Reprod. 2004;19(2):266-71.
17. Jurkovic D. Modern management of miscarriage: is there a place for non-surgical treatment?. Ultrasound Obstetr Gynecol. 1998;11(3):161-3.

18. Hurd WW, Whitfield RR, Randolph Jr JF, Kercher ML. Expectant management versus elective curettage for the treatment of spontaneous abortion. Fertil Steril. 1997;68(4):601-6.

19. Nielsen S, Hahlin M, Möller A, Granberg S. Pregnancy: Bereavement, grieving and psychological morbidity after first trimester spontaneous abortion: comparing expectant management with surgical evacuation. Hum Reprod. 1996;11(8):1767-70.

20. Sajan R, Pulikkathodi M, Vahab A, Kunjitty VM, Imrana HS. Expectant versus surgical management of early pregnancy miscarriages-A prospective study. J Clin Diagn Res. 2015;9(10):QC06.

Cite this article as: Kushwah B, Kushwah DS. A randomized controlled study on expectant management of incomplete abortions caused by self medication. Int J Basic Clin Pharmacol 2019;8:140912. 